\title{
Factores determinantes del Embarazo en Adolescentes Solteras
}

\author{
Dres.: Alberto Duarte-Contreras*, Alvaro Barreto-López**
}

\begin{abstract}
A principios de la década del 70, en un estudio que presentara uno de nosotros a la consideración de la Academia Nacional de Medicina sobre "Embarazo en Adolescentes de 11 a 15 años", decíamos que en la actualidad el embarazo aumentaba de manera epidémica en adolescentes "debido a la pubertad más temprana, a los matrimonios cada vez a menor edad, a la explosión de la cópula, a la nueva libertad sexual y al número de adolescentes que son aproximadamente el cincuenta por ciento de la población femenina", afirmación que tiene cabal válidez en nuestros días. (11).
\end{abstract}

El embarazo en niñas $y$ en adolescentes de corta edad es tan antiguo como la humanidad misma, si bien las comunicaciones científicas son de reciente data. En 1658 Mandeslo relata que una niña de seis años quedó embarazada (29); $\mathrm{Ha}$ ller en 1751 hace una magn ífica descrip-

\footnotetext{
* Ginecólogo del Servicio de Recién Nacidos y de la Consulta Externa de Ginecología Infantil del Hospital San Juan de Dios. Cúcuta, Colombia.
}

** Médico, Siquiatra del Hospital Mental Rudesindo Soto. Cúcuta. ción de la niña Anna Mimmenthaler quien presentara su menarca a los dos años y siete años más tarde diera a luz un niño normal $(21,25)$; Gould y Pyle informan en su libro "Anomalías y curiosidades de la Medicina" publicado en 1897 que Molitor atendió en 1878 una niña de Luxemburgo, nacida con vello pubiano, cuya menarca se presentó a los 4 años y quien dio a luz cuatro años más tarde (19); Dodd en 1881 informa que una señora española fue abuela a los 25 años y otra a los 28 (10). En América Latina tenemos el relato de Escomel en 1939 que informa sobre la niña peruana Lina Medina quien tuvo la menarca a los ocho meses y dio a luz una niña por cesárea a los cinco años y medio (14).

Sólo a partir de la segunda guerra mundial el embarazo en niñas y adolescentes ha tomado caracteres alarmantes hasta convertirse en conflicto social con el agravante que la mayoría de estos embarazos termina en aborto provocado, hecho que mina la salud física y mental, muchas veces con caracteres indelebles, de estos seres que apenas empiezan a vivir.

La menarca se presenta ahora a menor edad haciendo que la niña se convierta 
somáticamente en mujer adulta con una celeridad que espanta, Este hecho, más infinidad de factores socio económicos y culturales, facilitan el inicio de relaciones sexuales cada vez a menor edad, de manera irresponsable. En la actualidad, las adolescentes en general, incluyendo el grupo de mejores ingresos, inician sus relaciones sexuales a corta edad, lo que lleva a índices más altos de actividad sexual y a un mayor riesgo de embarazos no deseados (33).

La colaboración que aportásemos a un trabajo sobre Adolescencia (24), más los datos expuestos en nuestros estudios de investigación $y$ en el ejercicio profesional, nos demuestran que la menarca se presenta en nuestro medio tropical a los doce y medio años, si bien puede ser un poco más tardía en el altiplano andino $(11,12)$.

La niña, aunque suspira ansiosa por volverse adulta y se sienta importante por los cambios corporales que está observando, no quiere dejar de ser niña. Su madurez orgánica genital y reproductora se presenta con mucha antelación a la madurez emocional y de responsabilidad y más aún, a la capacidad de disfrute sexual (7). El hecho de presentarse una maduración somática sin maduración síquica equivalente, trae como consecuencia problemas afectivos por la elección del objeto sexual y como corolario, agresividad contra el medio social, familiar y escolar.

Recordemos que en el conjunto de manifestaciones bío-sico-sociales que caracterizan el paso de la infancia a la edad adulta, se debe individualizar: 1. el período prepuberal que va del inicio de aparición de los caracteres sexuales secundarios hasta la menarca, y 2 . la adolescencia que nosotros consideramos desde la menarca hasta los dieciocho años, o tres años después de la menarca, cuando ésta es retardada (1).
Según la Federación Americana de Planificación Familiar (33), en los Estados Unidos de Norteamérica, cada año se embaraza casi el $10 \%$ de las adolescentes y aproximadamente el $6 \%$ da a luz, o sea, alrededor de 700.000 jóvenes de 15 a 17 años, más unas 300.000 menores de 15 años, conciben cada año y la tercera parte de ellas aborta; más de las dos terceras partes son solteras. Así, los nacimientos en adolescentes solteras entre 1961 y 1970 aumentaron en el $75 \%(15,33)$; el problema se agrava aún más por el hecho de que una buena parte de las embarazadas son reincidentes $(20,36)$.

En nuestro país en una encuesta realizada en 1981 por CCRP. a 3.192 mujeres de 15 a 49 años sobre la edad en que tuvieron su primer embarazo se logró el siguiente resultado: (28)

EDAD DEL PRIMER EMBARAZO EN PACIENTES DE MENOS DE 15 HASTA LOS 18 AÑOS

\begin{tabular}{lrc}
\hline Edad & \multicolumn{1}{c}{$\%$} & $\frac{\circ}{5}$ acumulado \\
\hline Antes de los 15 años & 7.6 & 7.6 \\
15 a 16 años & 16.8 & 24.4 \\
17 a 18 años & 23.1 & 47.5 \\
\hline
\end{tabular}

Fuente C.C.R.P.

Este cuadro nos informa que al Ilegar a los 18 años, el $47.5 \%$ de las mujeres fértiles han dado a luz, hecho que nos obliga a investigar la problemática etiológica del embarazo a tan temprana edad.

Hay adolescentes que desean intensamente tener un hijo tanto como una niña anhela poseer una muñeca. Otras se ven impulsadas a la actividad sexual y por ende a la maternidad, por sus mismos familiares, sea por necesidad como por conveniencia. La mayoría se embarazan al llevar vida sexual activa persiguiendo otros tines: adquirir experiencia, identificarse con su madre, hermanas o 
amigas, venganza contra sus padres, retener al amigo, resolver conflictos inexplicados, dando como resultado un embarazo que en dos de cada tres casos es indeseado. Esto quiere decir que los embarazos extraconyugales en adolescentes no obedecen a una sola causa. Múltiples son los motivos que llevan a la adolescente a un emharazo de manera consciente o inconsciente. Sabemos que el embarazo a esta edad aumenta día a día $y$, entonces, la única manera de disminuirlo, o al menos de tornarlo en responsable, es tomando las medidas conducentes a aminorar algunas de las múltiples causas que vamos a encontrar y a estudiar. Este y no otro es el propósito de la presente investigación.

\section{MATERIAL Y METODOS}

Hemos encuestado y atendido a 300 adolescentes embarazadas, de 11 a 17 años, que solicitaron los servicios de Consulta Externa del Hospital San Juan de Dios, o del Albergue para madres solteras o nuestra consulta particular. Seguimos a todas hasta algún tiempo después de la finalización del embarazo por aborto o por parto. A unas les hemos podido hacer un seguimiento por varios años con miras a otros trabajos que estamos preparando. Es un trabajo prospectivo con material reunido en diez años, 1973 a 1983, que cobija adolescentes de todas las esferas económicas $y$ sociales. Todas estaban embarazadas en la primera consulta.

\section{RESULTADOS}

\section{Eciad de las Pacientes}

La edad osciló entre los 11 y los 17 años siendo la más representativa la comprendida entre los 15 y los 16 años (66.1)
EDAD DE LAS PACIENTES

\begin{tabular}{crrc}
\hline Edad años & No. & \multicolumn{1}{c}{$\%$} & \% acumulado \\
\hline 11 & 2 & 0.6 & \\
12 & 5 & 1.7 & 2.3 \\
13 & 27 & 9.0 & 11.3 \\
14 & 41 & 13.6 & 24.9 \\
15 & 83 & 27.7 & 52.6 \\
16 & 115 & 38.4 & 91.0 \\
17 & 27 & 9.0 & 100.0 \\
\hline \multicolumn{4}{c}{} \\
\hline
\end{tabular}

Desconcierta el hecho de que 34 niñas entre 11 y 13 años se encuentran embarazadas (11.3\%). Lo cierto es que ya están en pleno desarrollo sexual, en plena pubertad, vale decir, adolescentes desde el punto de vista ginecológico pero niñas desde el punto de vista síquico. Son éstos los casos que requieren un especial cuidado no sólo obstétrico sino sicológico y muchas veces más sicológico que obstétrico.

Son estos embarazos producto del deterioro de los hogares, de la falta de educación, del abandono en que están sumidas estas criaturas y del morbo social.

El 9\% pertenecían al grupo de 17 años; si bien es una cifra alta, la podemos considerar como aceptable al compararla con los grupos de 14, 15 y 16 años (78.7\%). Interviene ya a esta edad no sólo la maduración somática sino el control emocional, la transformación síquica y el desarrollo de aptitudes hacia un desempeño profesional.

\section{Estado Civil}

De acuerdo al protocolo del presente estudio todas las pacientes estaban embarazadas y eran solteras el día de la primera consulta. Las que abortaron se- 
guían solteras cuando se lo provocaron. En el momento del parto, 67 (23.3\%) habían constituido hogar, 23 por matrimonio eclesiástico o civil (34.3\%) y 44 por unión libre (65.7응).

\section{ESTADO CIVIL}

\begin{tabular}{|lccc|}
\hline & Solteras & Casadas & के \\
\hline Antes del embarazo & 300 & & \\
Abortaron siendo sol teras & 31 & & \\
En el momento del parto & 202 & 67 & 22.3 \\
\hline
\end{tabular}

De las 67 que se casaron antes del parto, 25 (37.3\%) lo habían realizado con jóvenes entre 17 y 19 años, vale decir con adolescentes inexpertos $y$ un tanto irresponsables.

En este grupo se encuentran algunas de las que buscaron el embarazo para asegurar el apoyo o el cariño de un determinado varón. Doscientas treinta y tres (77.7\%) ingresaron al inmenso grupo de adolescentes solteras que van a constituir un serio problema económico y social tanto para la familia como para el Estado y que, en cierto modo, van a depender de las Instituciones de Asistencia Social.

El día de la primera consulta 51 (17은) sospechaban o estaban seguras de su embarazo pero querían confirmarlo; 249 (83\%) desconocían cursar una gestación. Uno o dos meses después, 31 (10.3\%) habían tenido un aborto, seguramente provocado.

\section{Menarca}

Ninguna de nuestras pacientes tuvo pubertad precoz. Cuatro presentaron pubertad adelantada entre los 9 y los 10 años. La edad promedio de la menarca fue de doce años seis meses, cifra ésta acorde con la de otros estudios $(5,7$, $11,18,24,30,38$ ).

Una adolescente de 13 años fue Ileva- da por su madre a nuestra consulta por la presencia de un "tumor": no había menstruado aún y se le constató un embarazo de ocho meses. Seguramente había ovulado en el ciclo que precedió a la menarca.

MENARCA

\begin{tabular}{rrr}
\hline Edad & No. & \multicolumn{1}{c}{$\%$} \\
\hline 9 & 4 & 1.3 \\
10 & 7 & 2.3 \\
11 & 42 & 14.0 \\
12 & 114 & 38.0 \\
13 & 66 & 22.0 \\
14 & 44 & 14.7 \\
15 & 13 & 4.4 \\
16 & 4 & 1.3 \\
No recuerdan & 6 & 2.0 \\
\hline
\end{tabular}

\section{Relaciones Sexuales}

Tres niñas iniciaron relaciones antes de los 10 años cuando vivían en el campo; cuarenta y dos entre los 10 y los 12 años (13.9\%). La edad más frecuente la encontramos entre los 13 y los 15 años (63.6\%); luego, al iniciar la consolidación de la madurez síquica se inicia un descenso considerable.

Cinco jóvenes que estaban entre 16 y 17 años, pertenecientes a hogares deshechos, tenían embarazo de repetición; las cinco habían terminado su primer embarazo en aborto provocado (1.7\%).

\section{Constitución del Hogar}

Ciento veintisiete de nuestras pacientes procedían de hogares mal constitui- 
INICIO DE LAS RELACIONES SEXUALES

\begin{tabular}{cccc}
\hline Edad & No. & \% & \% acumulado \\
\hline 8 & 1 & 0.3 & 1.0 \\
9 & 2 & 0.7 & 3.6 \\
10 & 8 & 2.6 & 3.6 \\
11 & 12 & 4.0 & 7.6 \\
12 & 22 & 7.3 & 14.9 \\
13 & 44 & 14.6 & 29.5 \\
14 & 81 & 27.0 & 56.5 \\
15 & 66 & 22.0 & 78.5 \\
16 & 39 & 13.0 & 91.5 \\
17 & 18 & 6 & 97.5 \\
Sin dato & 7 & 2.5 & 100.0 \\
\hline & 300 & 100.0 & \\
\hline
\end{tabular}

dos o deshechos (42.4\%) lo que se debía a fallecimiento de alguno de los progenitores $(4.3 \%)$ siendo substituido prontamente por otra persona, o a separación permanente $(13.4 \%)$, o a separaciones repetidas y prolongadas $(22.4 \%$ ) durante las cuales, en algunos casos, se remplaza a la persona ausente. Algunas no conocen a uno de sus progenitores (2.3\%). Al faltar cualquiera de los padres, la identificación no se hace adecuadamente puesto que es en este momento de la adoles-

\section{CONSTITUCION DE SU HOGAR}

\begin{tabular}{|c|c|c|c|}
\hline & & No. & $q$ \\
\hline \multirow{3}{*}{ Familia constituida } & legalmente & 109 & 36.3 \\
\hline & & & \\
\hline & & 173 & 57.6 \\
\hline \multirow{5}{*}{$\begin{array}{l}\text { Familia mal } \\
\text { constituida }\end{array}$} & Fallecimiento & 13 & 4.3 \\
\hline & Separación & 40 & 13.4 \\
\hline & Ausencia & 67 & 22.4 \\
\hline & No conoce padres & 7 & 2.3 \\
\hline & & 127 & 42.4 \\
\hline
\end{tabular}

cencia cuando más se necesita de apoyo y al faltar uno de ellos, se busca o se acepta este sostén de otra persona, muchas veces sin saber las consecuencias.

Treinta y cinco progenitores eran adictos al alcohol o a la droga (11.6\%). El etilismo de los padres es factor influyente en la disgregación de la familia con influencias obvias en el comportamiento de los hijos.

\section{Estado Social y Primera Relación Sexual}

El alto índice de relaciones sexuales en adolescentes de clase socio económica baja se explica claramente al observar el gran número de niñas y jóvenes que deambulan por las calles de nuestras populosas ciudades, visitan fábricas, almacenes, oficinas, expendios, en busca de trabajo para lograr la subsistencia de su hogar, muchas de ellas ingénuas, recién llegadas del campo, ignorantes, faltas de malicia en su mayoría y ataviadas todas con las mejores prendas de vestir que les es posible. Son presa fácil bajo pretexto de darles un empleo, de convivir, de retribución monetaria, de regalos llamativos o de cariño "desinteresado".

Tres jóvenes de estrato social bajo, entre 13 y 14 años se inclinaron hacia ia vida sexual al observar las relaciones de

ESTADO SOCIAL Y PRIMERA RELACION SEXUAL

\begin{tabular}{lrrr}
\hline $\begin{array}{c}\text { Clase } \\
\text { social }\end{array}$ & No. & $\%$ & $\begin{array}{c}\text { Edad de } \\
\text { la primera } \\
\text { relación sexual }\end{array}$ \\
\hline baja & 223 & 74,3 & 8 a 16 años \\
media & 61 & 20.3 & 13 a 16 años \\
alta & 16 & 5.4 & 14 a 16 años
\end{tabular}


sus padres, dado el hacinamiento en que vivían. Otras recuerdan haber visto a sus padres en el acto sexual, sin que ello hubiese influido para el inicio de sus relaciones. Siete, también de clase baja, se iniciaron con incesto a corta edad: dos con su padre, dos con su padrastro $y$ tres con uno de sus hermanos mayores.

El $65 \%$ de las que se iniciaron antes de los 13 años, ignoraban lo que iban a hacer y más aún el riesgo que corrían de de quedar embarazadas.

\section{Estado Económico}

\section{COMO SE SOSTIENEN LOS HOGARES}

\begin{tabular}{lrrl}
\hline Salarios recibidos & No. & \multicolumn{1}{c}{ \& } & son ingresos \\
\hline uno o dos salarios & 200 & 66.6 & insuficientes \\
mínimos & 72 & 24.1 & bajos \\
tres a cuatro salarios & 12 & 4.0 & normales \\
recursos suficientes & 4 & 1.3 & excelentes \\
familia adinerada & 12 & 4.0 & \\
lo ignoran & 300 & 100.0 & \\
\hline
\end{tabular}

El mayor número de jóvenes provenía del grupo de hogares con ingresos insuficientes (66.6), los que iban de un salario mínimo no completo hasta dos salarios (entre siete y veinticuatro mil pesos al mes o sea entre 46 y 160 dólares). Setenta y dos (24.1) recibían entre tres y cuatro salarios, siendo algunos de ellos también inferiores al salario mínimo (entre veinte $y$ cincuenta mil pesos -133 y 333 dólares mes-). Doce $(4 \%)$ tenían recursos suficientes y cuatro (1.3\%) procedían de familias adineradas. Doce desconocen o no quieren informar cuál es el recurso económico de la familia.

No se debe confundir ni equiparar la clase social con la clase económica. Así, familias adineradas pueden corresponder a la clase social baja o media y familias de clase social alta pueden carecer de recursos económicos suficientes y estar entre la clase de recursos bajos o normales.

\section{Deserción Escolar}

ESCOLARIDAD

\begin{tabular}{lrr}
\hline Educación recibida & No. & \multicolumn{2}{c}{$\frac{8}{}$} \\
\hline sin estudio alguno & 65 & 21.7 \\
primaria incompleta & 141 & 47.0 \\
primaria completa & 75 & 25.0 \\
secundaria incompleta & 11 & 3.7 \\
bachillerato - secretariado & 5 & 1.6 \\
universitaria - técnica & 3 & 1.0 \\
\hline & 300 & 100.0 \\
\hline
\end{tabular}

Al practicar la primera consulta, sesenta y cinco eran analfabetas (21.7\%); ochenta y cinco habian suspendido sus estudios antes del embarazo por diferentes razones $(27.3 \%)$, y sólo ciento cincuenta y tres (51\%) asistían a sus clases en horarios diurnos o nocturnos. Cincuenta $y$ dos (17.3) trabajaban y estudiaban.

Una vez que estas 153 jóvenes tuvieron conocimiento de su embarazo, desertaron 130 (84.9\%) y solamente 23 (15.1\%) prosiguieron sus estudios ya que tenían la seguridad de constituir hogar.

\section{Anticoncepción}

Cuarenta y siete ignoraban el riesgo de quedar embarazadas (15.6\%), en tanto que $253(84.4 \%)$ ten ían pleno conocimiento de lo que hacian, pero, o deseaban el embarazo, o estaban en la seguridad casi completa de que no concebirían. Ocho creían que por ser tan jóvenes no serían embarazadas y tres estaban convencidas de que al tener coitos esporádi- 
cos y distanciados no había posibilidad de gestación.

POSIBILIDAD DE EMBARAZO

\begin{tabular}{lrl}
\hline & No. & \% \\
\hline Sabían la posibilidad & 253 & 84.4 \\
La ignoraban & 47 & 15.6 \\
\hline
\end{tabular}

El grupo que desconocía la posibilidad de quedar embarazada al tener relaciones sexuales estaba compuesto por jóvenes de diez a catorce años; es la muestra más significativa del desconocimiento sexual en lo que tienen culpa tanto la madre como las educadoras. Si hay la resolución de trabajar para disminuir el embarazo en adolescentes solteras, no cabe la menor duda de que una de las primeras cosas que se debe enseñar a la premenárquica es la fisiología de la reproducción.

Al preguntarles sobre métodos anticonceptivos, sólo 182 (60.7\%) tenían algún conocimiento al respecto. Ciento dieciocho los ignoraban (39.3\%). En este momento ninguna seguía método anticonceptivo bien fuese por ignorancia del riesgo de embarazo, o por desconocimiento de los contraceptivos, o porque estaba buscando el embarazo. Cuarenta y seis (15.3) los habían usado anteriormente.

\section{ANTICONCEPCION}

\begin{tabular}{lcc}
\hline & No. & $\%$ \\
\hline conocen métodos & 182 & 60.7 \\
los desconocen & 118 & 39.3 \\
\hline
\end{tabular}

\section{Trabajo}

La profesión de copera en nuestro medio es sinónimo de prostituta $y$ de inasistente a aulas escolares. Este grupo vive expuesto a la drogadicción, a la cri- minalidad y agrupa, como es lógico, a las jóvenes de menor edad dada su inexperiencia, su falta de responsabilidad y sus atractivos físicos (13).

\section{EN QUE TRABAJAN}

\begin{tabular}{lrr}
\hline & No. & \multicolumn{1}{c}{$\%$} \\
\hline copera & 13 & 4.3 \\
prostituta & 12 & 4.0 \\
empleada & 45 & 15.0 \\
servicios domésticos & 29 & 9.7 \\
obreras & 20 & 6.7 \\
no trabajan & 181 & 60.3 \\
\hline
\end{tabular}

Las empleadas son todas de segunda categoría: aseadoras, vendedoras en almacenes o ambulantes, mensajeras o atienden oficinas de profesionales. Las obreras no son calificadas. Tanto las empleadas como las domésticas y las obreras estudian en horas de la noche. Ciento ochenta y una no trabajan.

\section{COMENTARIOS}

Parece un pleonasmo decir embarazo en adolescentes solteras, teniendo en cuenta que la Iglesia no permite que la mujer se case antes de los 14 años y que el Estado no atestigua el matrimonio civil a mujeres menores de 16 años. No lo es, ya que muchas constituyen hogares en unión libre desde muy temprana edad, en busca de seguridad socio-económica y estabilidad emocional.

Estudiamos nuestras pacientes desde el punto de vista biológico, socioeconómico-cultural, familiar y sicológico.

Desde el punto de vista biológico no tuvimos en cuenta el aspecto racial ya 
que en nuestro medio la mayoría de los habitantes urbanos y rurales son de raza blanca. Se dice que por lo general la mujer de raza negra tiene su menarca muy temprana y que la mayoría pertenece a la clase socio económica baja.

Es bien sabido que la menarca se presenta cada vez a meror edad con el correr del tiempo. Diferentes estudios han demostrado que en los Estados Unidos entre 1934 y 1966 hubo un descenso de 10 a 12 meses en la aparición de la menarca, habiéndose presentado en 1968 a la edad promedio de 12.65 , más o menos 1.2 años (39). Trabajos realizados en Europa demuestran que en el viejo continente se ha presentado a menor edad cada 100 años, a razón de 3 a 4 meses por década (40).

Botella opina que no parece haber una exacta correlación entre la latitud, el clima y la aparición de la menarca (6). Nosotros, por la diaria observación en nuestro ejercicio profesional, disentimos de esta opinión. Factores raciales, el medio de vida y ciertas influencias geológicas como la composición de las aguas, pueden modificar también la edad de la menarca.

Puesto que el hipotálamo, en el caso de la pubertad, marca la hora del despertar sexual comportándose como el reloj del organismo, creemos que entre mayores conflictos viva la niña y entre mayor acoso sufra en la sociedad, como sucede en la era moderna, este estrés actúa fuertemente sobre el hipotálamo haciendo que la menarca se presente cada vez a menor edad, participando como coadyuvante el adelanto médico en beneficio del bienestar somático.

La menarca en diferentes latitudes, continentes $\mathrm{y}$ países, se presenta a edades que van de los 12 a los 16 años, debiéndose esta disparidad a una prolija serie de condiciones, incluyendo la genética.
La aparición temprana de la menarca, que se asocia siempre a la presencia de caracteres sexuales secundarios, más no a un desenvolvimiento sicológico acorde al rápido desarrollo sexual, despierta en las niñas, que de un momento a otro y sin preparación alguna se sienten mayores, una serie de reacciones, de problemas que agravan el conflicto y lo tornan casi en un síndrome de desadaptación emocional puberal (7).

La niña al llegar la menarca, al sentirse mujer, se cree liberada en todos los aspectos de su vida, máxime cuando le apoya el sentir de un grupo considerable de mujeres de todas las edades, que predican, sienten, $y$ viven en independencia casi absoluta de todo vínculo que las retenga en el hogar, dentro del núcleo familiar. La niña quiere estudiar cuando le plazca, vestir a su manera, entrar y salir de casa a cualquier hora, asistir a cuanta reunión capte su atención, convivir con grupos heterogéneos imitando sus costumbres, en fin, revelarse contra toda norma de conducta que le "oprimía" hasta entonces.

La menarca temprana se constituye en el despertar brusco a una vida nueva, de libertad, de choque, de protesta, de rebeldía, sin obligaciones pero con grandes derechos en el ámbito familiar y social.

Este desarrollo biológico y sexual precede siempre al desarrollo intelectual y éste al sicosocial. La adolescente, entonces, a través de estos procesos busca su independencia afectiva, establece su identidad y desarrolla su sexualidad $y$ es por ello por lo que la adolescencia se caracteriza por ambivalencias que marcan el desenvolvimiento de la persona.

Por lo general hay un período más o menos corto, de 6 a 36 meses, en el cual los ciclos son anovulatorios; marca este lapso un período de esterilidad post- 
menárquica, período que constituye una época de anticoncepción fisiológica. Se presentan, también, casos en los cuales la ovulación es inmediata a la menarca, y aún, afortunadamente poco frecuentes, en los días que la preceden como lo hemos observado al atender a una jovencita de 13 años embarazada que no había conocido la menarca. De modo que este período de esterilidad postmenárquica fisiológica, no se puede tener como regla fija. Para confiar en él es preciso emplear algún método de fácil ejecución y valoración que indique si los ciclos son ovulatorios o anovulatorios tal como el de temperatura basal, el de moco cervical o la citología funcional seriada.

Al hablar de relaciones sexuales no tenemos en cuenta las violaciones, sino aquellos actos en los cuales, por un motivo u otro, así fuese el engaño, la niña se entregó al pretendiente. $Y$ no decimos se entregó "voluntariamente" porque a esta edad la niña tanto por fal ta de conocimientos como de juicios adecuados es incapaz de discernir y tomar decisiones ante actitudes tan complejas como el inicio de las relaciones sexuales. En nuestras pacientes mayores de 13 años la entrega fue casi siempre voluntaria $y$ aceptada, así no estuviesen capacitadas para prever los riesgos y obligaciones que esta actitud les pudiera acarrear.

En ocho pacientes (2.62\%), el galanteo que precedió a la primera relación fue tan placentero que conservaron su recuerdo y lo mimaron con agrado, hecho que, en contra de lo que generalmente se afirma, despertó un deseo de placer y satisfacción sin control y sin responsabilidad, como el que pudiera sentir por su mejor juguete. Volcán éste que erupciona con ímpetu y que la sociedad alimenta con fervor a base del consumo de propaganda permanente por radio, televisión, prensa y revistas puestas libremente al alcance de todas (9). Pero a su vez, aun cuando ninguna formó hogar, constituyeron un grupo que por lo general pudimos orientar con facilidad, con la ayuda de ejemplos de embarazos, de venéreas, de droga, de delincuencia, de purga de penas acaecidas en amigas o en familiares o en niñas de su misma edad. Desafortunadamente algunas de las de este grupo se dedicaron a la prostitución clandestina, al vicio de la droga y al "raponeo".

Observamos que las niñas de 10 a 13 años que ya viven en concubinato tienen una comprensión especial por su varón más acentuada que la que observáramos en las mayores. Seguramente la corta edad hace que transfieran en plenitud a su compañero, el cariño, el respeto y la obediencia que le deben a su padre, así antes no la hubiesen sentido ni demostrado. Pero por lo general, estas mismas niñas al llegar a una edad mayor, 15 a 17 años, abandonan este estado de "humiIlación $y$ de esclavitud a las que estábamos sometidas" según sus palabras, para regresar unas al hogar paterno solas o tal vez con uno o más hijos o para ir en pos de otra sombra de mayor follaje, o para entregarse a la vida libre sin preocupación y sin deberes.

Las que iniciaron relaciones a los 16 o 17 años, lo hicieron con conocimiento de causa, si bien, sin saber algunas veces o sin interesarles otras, el riesgo a quedar embarazadas.

La motivación de tipo social para la iniciación temprana a las relaciones sexuales tiene diversos factores. En las clases bajas puede obedecer a la necesidad de supervivencia, si bien se ve facilitada por problemas incestuosos, o por el hacinamiento al vivir en tugurios o en casas de inquilinato, llegando con facilidad a la promiscuidad o a la prostitución: tal sucedió con siete de nuestras pacientes cuya primera relación fue incestuosa. En la clase media casi siempre se debe al contagio de querer imitar la conducta de quienes la rodean o de emular al resto de familiares $y$ amistades. En las clases altas 
puede deberse primordialmente a la liberalidad con que se mira lo sexual, llamado amor libre, al cual se llega algunas veces por falta de vigilancia de los padres quienes se dedican a sus actividades sociales en detrimento del cuidado de sus hijos.

Encontramos el embarazo de repetición en cinco pacientes cuyos hogares estaban deshechos; su embarazo anterior había terminado en aborto. Parece que el embarazo repetido en adolescentes solteras se encuentra en jóvenes que provienen de hogares deshechos o en alumnas que han fracasado en sus estudios y cuyas relaciones familiares empeoraron con el primer embarazo; al practicarles pruebas sicológicas se les encuentra un ego de fuerza limitada (2).

Cuatro tuvieron relaciones héterosexuales para convencerse o para demostrar que no eran homosexuales como decían sus amigas.

Nueve se daban perfecta cuenta del rechazo al padre por parte de la madre, cuando éste era "un padre responsable y bueno"; para castigar el proceder materno buscaron un hombre a quien satisfacían a plenitud, sin pensar jamás en la posibilidad de un embarazo.

Algunas adolescentes se agobiaron después de la primera relación sexual, con sentimiento de culpa, de vergüenza o de temor; otras sintieron una desenfrenada manifestación de hipersexualidad. Para unas el acto sexual pasó como un accidente cualquiera en su noviazgo y lo aceptaron pasivamente para conservar a su amado. Para otras la relación sexual fue un acto de simple curiosidad y finalmente hubo quienes se sirvieron de su conducta sexual para rebelarse contra los padres. Es que los factores sicológicos, sociales, culturales, éticos, morales y religiosos afectan la respuesta sexual de la joven en gran escala (9).
El rechazo al embarazo fue más notorio y vehemente en las más jóvenes, y por ésto en ellas las náuseas, el vómito se presentaron por tiempo prolongado y la toxemia, el parto antes de tiempo y los productos de bajo peso se observaron con mayor frecuencia que en pacientes de más edad.

Más del $50 \%$ tienden a negar el embarazo y tratan de explicar de diferentes maneras la sintomatología que presentan: amenorrea, aumento de peso, crecimiento del volumen del abdomen, el estado nauseoso, los vómitos, entre otros.

Una vez confirmado el diagnóstico son conscientes de un hecho real y positivo y entonces viene el dilema: callar o huír, enfrentarse ante sus padres, ante sus profesores, ante la sociedad con la realidad del problema sicológico y өconómico cuando aún son hijas de familia y dependen plenamente del peculio familiar? ¿Decirle al novio u ocultarle? y cuando no hay certeza de quién sea el padre, ¿qué hacer? Entonces algunas revelan el nombre del padre, de su futuro hijo, otras lo ocultan y otras nada dicen pues no saben quién pueda ser (16).

En escasas oportunidades los padres recapacitan, se sienten culpables y colaboran solícitamente con su hija: ello requiere criterio, formación moral, principios éticos y educación, bases de un hogar organizado. En otras, el padre monta en cólera, amenaza, golpea y hace recaer toda la culpa en la madre por la falta de cuidado hacia su hija; vienen las recriminaciones, los insultos con palabras altisonantes y el ambiente familiar empeora, se deteriora, se torna invivible y hasta se deshace, comprometiendo así la supervisión y la educación de los demás hijos (37).

La decisión del aborto generalmente es externa y ajena; casi siempre la joven culpa a sus padres como instigadores de esta errada solución que puede ahondar 
más aún la división hogareña, hacer perder el cariño por los progenitores y aumentar la depresión (22). Estas secuelas las encontramos en las reincidentes e hicieron que la reacción de culpa fuese mayor que los sentimientos de odio y agresión que provocan el hijo no deseado. Después del aborto queda el dolor por la muerte de un hijo que alcanzó a imaginar y por la pérdida de una maternidad soñada (17).

El matrimonio entre parejas muy jóvenes, como el realizado por 25 de nuestras pacientes, casi siempre es un fracaso. Son esposos sin mayor responsabilidad, sin trabajo ni profesión estable, que tienden de por sí a presentar desajuste y disgregación familiar (34).

Diecisiete pacientes de las de mayor edad y de estrato socio-económico alto formalizaron matrimonios con personas de su mismo nivel, profesionales casi todos, mayores de edad, con trabajo o profesión estable y lucrativa, pero fueron matrimonios forzados por un embarazo; no fueron matrimonios espontáneos incubados en el cariño mútuo y respetuoso, sino al contrario, maquinados unas veces, consecutivos a una celada urdida por la adolescente o por algún familiar con la única mira de asegurar el porvenir de la joven. Si un matrimonio, a pesar de haber nacido del amor y de haberse efectuado de manera responsable $y$ espontánea encuentra dificultades y en oportunidades llega hasta el fracaso, ¿qué no ocurrirá cuando es producto de traición o de obligación? En estos matrimonios no se encuentran las condiciones necesarias para asumir la responsabilidad de un hogar ya que son la consecuencia de un embarazo ilegal o extramatrimonial. Al hablar de matrimonio nos referimos al matrimonio legal o a la unión libre.

El hecho mismo de que un menor o mayor de edad embarace a una adolescente, novia o amiga, habla muy a las claras sobre su irresponsabilidad ya que hubiese podido evitarlo. Seguramente en un futuro inmediato seguirá dando muestras de irresponsabilidad por algún tiempo, el suficiente para acabar con el matrimonio y para hacer del hogar un sitio de tortura y de padecimiento, constituyendo así el matrimonio en un problema, semillero de nuevos desafueros en sus descendientes.

Las adolescentes de clase económica baja procedían de hogares compuestos por cinco a doce hijos y de dos a cinco hijos los de clase económica pudiente. Las familias muy numerosas, cuando corresponden a estratos económicos bajos, se constituyen en las mejoras aportadoras a la deserción escolar y al ya crecido número de desocupados.

Al estudiar la constitución de estas familias vale la pena oír las quejas que con mayor frecuencia expresaron las hijas.

En relación al padre decían: no lo conozco pues se fue de la casa cuando era pequeña; lo conozco pero no ve de mí; quiere a mis demás hermanos, más no a mí; no atiende a las necesidades de la casa sino en mínima parte a pesar de que gana bien y debo trabajar para ayudar a mamá; no me deja estudiar; es un tirano y me castiga con brutalidad; me trata con groserías; recibo mal ejemplo pues tiene todos los vicios imaginables; mi papá se fue y vivo con un padrastro que me quiere seducir; dejó a mi mamá y me llevó a vivir con la nueva compañera; mi madre tuvo que huir de la casa; mi padre o mi padrastro me echaron de la casa; mi papá se aprovechó de mí. Estas y muchas más son las quejas que airadas unas, desconsoladas y sollozantes otras, profieren contra el "hombre ése".

También hay quejas muy serias contra la madre: mi padre es un buen hombre pero mamá lo trata muy mal, lo va a correr; somos muchos hermanos pero to- 
dos de diferente papá; mi madre flirtea aún delante de mí; mi madre toma mucho; mi madre me ha propuesto tenga relaciones sexuales con determinados señores a cambio de buena paga o de otros beneficios, como el matrimonio; es muy cruel conmigo; abandona el hogar con suma frecuencia y yo sé qué está haciendo.

Otras quejas van contra la pareja: se insultan a todas horas y se tratan muy mal delante de mí sin tener en cuenta la tristeza que me da al oír lo que se dicen; siempre están fuera de casa y me dejan sola; no se preocupan por mis amistades y puedo hacer lo que quiera; me sacan en cara lo que han gastado en mi estudio; no me permiten estudiar y me obligan a trabajar; pudiendo no me dan lo que necesito; en casa tengo todo, hasta cine rojo, pero me falta cariño; se comportan como si fueran mis enemigos; nunca encuentro en ellos receptividad, no me escuchan; no me comprenden; no tengo en quién confiar; debo buscar muchachos para distraerme.

También hay quejas contra los hermanos mayores $y$ familiares con quienes conviven, todas en relación a que las tratan de engañar o de seducir de mil maneras; otras han tenido relaciones incestuosas.

Pero hay algunas confidencias lamentables: mi padre ha estado preso por robo, pobrecito ! no encontraba trabajo y era la única manera de podernos sostener y mientras tanto yo salía a rebuscarme; mi madre es sóla, sin recursos o no recibe ayuda y por ésto tiene sus amigos que le proporcionan dinero $y$ yo por lástima le colaboro.

Como reacción de estas jóvenes, tres fueron las más frecuentes: para vengarme me volé con un muchacho; para que les doliera me dejé erribarazar; para no estar sola busqué con quien vivir.
Es de anotar que aún cuando las quejas contra algunas madres se presentaron con dureza, ninguna les faltó al respeto, hecho muy diferente con lo ocurrido en relación al padre.

Tanto el medio ambiente como el familiar tienen gran importancia como factor determinante de estos embarazos. Suele hallarse siempre en el hogar de estas jóvenes falta de calor familiar, de cariño, de atenciones, de diálogo, de receptividad, de comunicación, a más de privaciones de lo necesario para la persona o para el estudio, hecho que las lleva a la insatisfacción y a la frustración; pero de lo que más se adolece, más que de lo material, es del respeto y del buen ejemplo ya que se presentan a diario discusiones violentas y groseras, agresiones de hecho, ausencia del hogar, asedio de conquista por parte del padre, del padrastro, de los hermanos y familiares cercanos, causas todas de desasosiego $y$ de angustia, mas contactos heterosexuales a muy corta edad o de fracaso en los estudios (4).

El distanciamiento de la madre lleva a la adolescente a buscar amistades con jóvenes o con mujeres de mayor edad que les pueden ser perjudiciales e inducir a la vida sexual activa, ya que les falta el consejo y la supervisión materna. Este distanciamiento las lleva en algunos casos a la búsqueda exagerada del padre, lo que puede representar una amenaza incestuosa inminente; al hacer conciencia de ello, se inicia un estado permanente de ansiedad, se altera el comportamiento y busca como defensa la entrega a otro hombre (2).

Hay ciertos hechos que minan la moral de la joven, la deprimen, la postran y hacen que la tercera parte de estas adolescentes sientan un deseo consciente de embarazarse para llenar con su hijo el vacío afectivo dejado por algo que han perdido. Tal sucede cuando muere el 
novio o alguno de sus padres, o cuando los padres se separan o divorcian, o cuando pierden un trabajo que les era muy placentero (27). La necesidad de compañía, de ternura, de un alivio a su soledad, les hacen buscar personas y grupos con los que pueda alcanzar intimidad, los que a la postre se constituyen en presión hacia la relación sexual (3).

El correr el riesgo de un embarazo puede ser una manifestación superficial de una problemática sicológica profunda, como disminución de autoestima, falta de afecto hacia sí misma o hacia los padres, falta de identificación con la imagen femenina de la madre, exclusión de afecto a la madre para entregarlo todo al padre, hechos que sin duda influyen en el comportamiento de no usar métodos anticonceptivos (35).

En nuestras pacientes, veintisiete (9\%) tenían conflictos con la madre, cuarenta $y$ siete (15.6\%) con el padre y quince $(5 \%)$ con los dos. Nos llamó la atención el hecho de que cuando había conflictos con la madre, desbordaban un gran aprecio por una hermana mayor o en su defecto por una familiar mayor $y$ algo similar sucedía, pero con familiares varones cuando el conflicto era con el padre. $\mathrm{Si}$ el conflicto era con los dos progenitores, la persona de su preferencia era entonces un varón mayor, hecho que ya han notado otros investigadores (7).

Al confirmar el diagnóstico del embarazo, unas huyen de sus hogares por temor; otras por pena no vuelven a la escuela o al colegio, o no les es permitido continuar estudios dada su gestación, o el compañero no les tolera salir de casa. Otras, a quienes no les agradan los libros, aprovechan esta coyuntura para abandonar definitivamente la educación escolar. Desafortunadamente esta deserción casi nunca es transitoria sino definitiva, cerrando así horizontes promisorios por falta de preparación intelectual. Es ésta la fatal de deserción escolar que tanto repercute en la constitución y comportamiento de una sociedad.

Todos los factores emocionales y físicos inherentes al embarazo circundan a la adolescente y aumentan su ansiedad. Vergüenza, culpa, fracaso, todo junto, atormenta su vivir. Más tarde, si es que encuentra receptividad en el hogar paterno, puede llegarle la alegría del hijo por nacer; de lo contrario el temor al aborto o al parto o al enfrentamiento real económico para sí y para su retoño, agravan su ansiedad y la pueden llevar a la desesperación, a la prostitución y al suicidio.

Sarrel da un pronóstico pesimista a la adolescente soltera embarazada al decir: “es el principio de un ciclo constituido por la interrupción de la educación, la dependencia de las Instituciones de asistencia pública, la carencia de una familia establecida y una serie de partos de hijos ilegítimos. Va a ser al final, una madre soltera con cinco o seis criaturas, deprimida, derrotada y dependiente" (36). Contra este pesimismo es contra el que debemos trabajar quienes nos dedicamos de lleno a la atención de estas pacientes.

Cutright añade: "un hijo ilegítimo reduce las posibilidades de matrimonio para la mujer y aumenta sus riesgos de penalidades y pobreza. Al dar a luz son ya pobres y la llegada de un hijo tiende a empeorar aún más la situación económica de la madre" (8).

Aún cuando el embarazo extramatrimonial ya no es en nuestros días estigma, ni ignominia, ni motivo de aprobio, sino que se le considera como una situación normal, la adolescente todavía huye y se esconde. Sólo las que cursan estudios universitarios o profesionales, por los reglamentos mismos de las Instituciones, a más de las que se casan, siguen frecuentando las aulas escolares y amistades. 
Conocidos los factores determinantes del embarazo en adolescentes solteras sólo nos resta trabajar con ahinco para buscar su solución.

\section{CONCLUSIONES}

Con los datos suministrados por las pacientes de la presente investigación, podemos decir que las causas del embarazo en adolescentes solteras se pueden enmarcar en cuatro grupos bien definidos, pero a su vez muy relacionados entre sí: causas biológicas, socio-económico-culturales, familiares y sicológicas.

La preparación para la menarca no consiste en la enseñanza de cuanto se relacione con el sangrado genital, sino primordialmente en dar una preparación sicológica, moral y sexual para el logro de resolver satisfactoriamente una serie de conflictos que despierta su presencia.

Se debe apoyar toda campaña de alfabetización con miras a suministrar la mejor capacitación posible.

Convivir en casas de inquilinatos y en tugurios constituye el factor principal de hacinamiento, una de las causas más frecuentes en la proliferación del inicio de relaciones sexuales a muy corta edad. Favorece también el incesto.

La desidia en el control de los medios de comunicación tiene marcada influencia en el fomento de la vida sexual activa.

Los hogares mal constituidos, cuando no priman el respeto, las buenas costumbres, la supervisión de los padres, son la mejor escuela para alterar el equilibrio emocional y el comportamiento de los hijos.

La desintegración de los hogares hacen que las niñas pierdan la identificación con los padres, presenten proble- mas de desadaptación familiar y escolar y busquen imágenes de substitución fuera del conglomerado familiar.

Todos los factores anteriores, más el estado socio-económico bajo y la pérdida de la moral, son coadyuvantes primordiales en la afluencia de embarazos en adolescentes solteras.

Aún cuando el embarazo en adolescentes solteras es visto por la sociedad contemporánea como un hecho normal, acarrera una alarmante problemática personal, familiar y social y constituye una espectativa que ensombrece.

Tanto la comunidad como el Estado están en la obligación de encausar todo el esfuerzo y recursos necesarios para buscarle solución a esta serie de factores determinantes del embarazo en adolescentes solteras.

\section{RESUMEN}

Se estudian trescientas adolescentes solteras de diferentes estratos socioeconómicos. La edad oscila entre $10 \mathrm{y}$ 17 años. La menarca se presentó a los doce años seis meses. Algunas iniciaron relaciones sexuales a muy temprana edad. Los embarazos, casi en su totalidad, fueron no deseados. Los embarazos deseados perseguían fines especiales: conservar al compañero, lograr ayuda económica o forzar a un matrimonio. Las causas que se encontraron con mayor frecuencia fueron: desintegración familiar, frustraciones, falta de calor hogareño, frac:aso en el estudio, venganza contra los padres, pobreza, hacinamiento. Es muy notoria la ignorancia sexual. La deserción escolar se hizo manifiesta. El incesto es frecuente. Se hacen comentarios. Se sacan conclusiones. 


\section{BIBLIOGRAFIA}

1. ALDOVANDRI, C.C., ARAUJO, M.M. L., FILHO, E.N., de MELO, G.D.M. Y DELASCIO, D. Factores etiológicos de reproduçao na adolescẽncia. Trabajo presentado al VI Simposio mundial de Ginecología pediátrica y de la adolescencia. Punta del Este, Uruguay, diciembre 1981

2. ALBERNETHY, V. Illegimitate conception among teenagers. Am. J. Psychiatric. 64: 662, 1974.

3. ANDREW, B.D., ARTHUR, T.F. Medical and social factors affecting early teenager pregnancy. Am. J. Obstet. Gynecol. 125: 532, 1976.

4. BARGLOW, P., BORNSTEIN, M., EXUM, D., WRIGHT, M. V VISOTSKY, H. Some psychiatric aspects of illegitimate pregnancy in early adolescence. Am. J. Orthopsychatry. 38: 672, 1963.

5. BARRIOS, A.J.A., RAMOS, O.A. y cols. Aspectos perinatales de las adolescentes. Rev. Colomb. Obst. Ginec. 36: 182, 1985.

6. BOTELLA, LL.J. La Pubertad. En: Endocrinologia de la mujer. Ed. Científico Médica. Barcelona. 4a. ed. 283, 1966.

7. CORDOBA, P.R. EI adolescente y la Sexualidad. Memorias del segundo curso de actualización médica Cafam. Medicina del Adolescente. 85. 1982.

8. CUTRIGHT, P. Illegitimacy: the prospect for change. Am. J. of Public Health. 63: $765,1973$.

9. DE LUCA, L.O. O problema sexual da adolescente. 1a. Ed. Almed. 1980.

10. DODD, $H$. Remarkable case of early maternity. Lancet. 1: 601, 1881.

11. DUARTE-CONTRERAS, A. Embarazo en adolescentes de 11 a 15 años. Temas
Médicos, Organo Oficial de la Academia Nacional de Medicina. Ed. Stella, Bogotá, 365, 1974.

12. DUARTE-CONTRERAS, A. El embarazo en adolescentes es siempre de alto riesgo? Rev. Colomb. Obstet. Ginecol. 26: 385, 1975.

13. DUARTE-CONTRERAS, A. Embarazo y prostitución en adolescentes. Rev. Colomb. Obstet. Ginecol. 30: 1, 1979.

14. ESCOMEL, E. La plus jeune mére du monde. Press. Med. 47: 875, 1939.

15. GHISLAINE, D.G. EI embarazo en las adolescentes solteras. En: Aspectos sicológicos en ginecología y obstetricia. Ed. Presencia Ltda. Bogotá, 95, 1982.

16. GODENNE, G.D. The pregnant school girl. En: Social responsability of gynecology and obstetrics. Barnes, A.C., Johns Hopkins Press, ed. Baltimore, 1965.

17. GODENNE, D.D. The unwe mother. En: International Enciclopedy of Psychiatry, Psochology, Psychoanalysis and Neurology. Wolman, B.B. Ed. Van Nostrand Reinhold-Aesculapius, Boston. 1977.

18. GOMEZ, P.J.A. Obstetricia en adolescentes. Rev. Colomb. Obstet. Ginecol. 23: 353, 1972.

19. GOULD, G. y PYLE, W. Anomalies and curiosities of Medicine. Philadelphia, Saunders W.B. Ed. 1897.

20. GUSTAVAS, S. Y NAM, C. Formation and stability of ideal family size among young people. Demography. 7: 43, 1970.

21. HALLER, A. Citado por Jolly, 1955.

22. HATCHER, S.L.M. Adolescence experience of pregnancy and abortion: a developmental analysis. J. of. Young and adolescence. 2: 53, 1973. 
23. HUFFMAN, J.W., DEWHURST, C.J. Y CAPRARO, V.J. The Ginecology of chilhood and adolescence. Chilhood and adolescent pregnancy. W.B. Saunders Co. Ed. Philadelphia. 1981.

24. JARAMILLO, U.R. Adolescencia Rev. Colomb. Obstet. Ginecol. 33: 1984.

25. YOLLY, H. Sexual precocity. Oxford, Blackvell Scientific Publications, 1955.

26. KLEIN, L. Antecedentes del embarazo en adolescentes. Clin. Obstet. y Ginecol. 4: $1199,1978$.

27. LOESCH, J. y GREENBERG, N. Some Specifit areas of conflit observed in pregnancy: a comparison study of married and unmarried pregnant women. Am. J. of Orthpsychiatry. 32: 624. 1962.

28. LOPEZ, E.G. y RIAÑO, G.G. La embarazada adolescente. En: Avances en Ginecología y Obstetricia. C.C.R.P. 14: 1979.

29. MANDELSLO. Voyage en Moscovic. $212,1652$.

30. MOLITOR. L'art Médicale. Brussels, 1878.

31. OSOFSKY, H. Teenage out of wedlock pregnancy. Some preventive considerations. Adolescence. 5: 151, 1970.

32. PITTMAN, V. Childbirthd at the age of nine. Am. J. Clin. Med. 15: 798, 1908.
33. Planned Parenthood Federation of America, Inc. 11 million teenagers. What can be done about the epidemic of adolescent pregnancies in the United States? New York, Alan Guttmacher Institute. 1976.

34. POLTO, J.J. El embarazo en la adolescente: un riesgo psíquico. Memorias del VI Simposio Mundial de Ginecología Pediátrica y de la adolescente. Punta del Este, Uruguay, 25, 1981.

35. RUSSEL, J.K. Actividad sexual y sus consecuencias en mujeres de 13 a 19 años de edad. Clin. Obstet. Ginecol. 683, 1974.

36. SARREL, P.M. y DAVIS C.D. The young unwed primiparas. Am. J. Obstet. Gynecol. 95: 722, 1966.

37. SHAFFER. R. Ansiedades específicas del embarazo. Psicología del embarazo, parto $y$ puerperio. Ediciones Kargienan. 1977.

38. UCROS, C.A., CASAS, L. Y UCROS, R.S. EI adolescente en Colombia. Variables fisiológicas del desarrollo pondo estatural y sexual. En: Medicina de Adolescente. Montoya y Araujo. Ed. Bogotá, 21, 1981.

39. ZACHARIAS, L. Y WURTMAN, R.J. Age at menarche. N. Engl. J. Med. 280: $868,1971$.

40. ZAIGUER, B.K. de. Embarazo en la adolescente. En: Ginecología infanto Juvenil. Ed. Panamericana, Buenos Aires, 309, 1977. 